\title{
A varíola, uma antiga inimiga
}

\author{
Smallpox, an old foe
}

Hermann G. Schatzmayr 1

1 Departamento de Virologia, Instituto Oswaldo Cruz, Fundação Oswaldo Cruz. Av. Brasil 4365,

Rio de Janeiro, $R J$ 21040-360, Brasil.

hermann@ioc.fiocruz.br
Abstract Smallpox has accompanied mankind for centuries, causing deaths and permanent lesions. Used in the past as a biological weapon during wars, it has come into focus again precisely because of this renewed possibility, although the disease has been eradicated in the Americas since 1971 and worldwide since 1977. Data gathered during the eradication campaigns show that the disease spread relatively slowly through close contacts between patients and susceptibles. Sub-clinical infection in non-vaccinated individuals was a rare event, and blockade vaccination surrounding new cases (as long as these cases were confirmed early) was able to prevent the disease from spreading in the community. Even with only one dose, vaccinated individuals rarely developed a serious case of the disease upon reinfection. The use of smallpox as a biological weapon should be considered a real possibility, although according to the available data, highly virulent viral suspensions spread very close to the target population would be necessary to infect a large number of persons.

Key words Communicable Disease Control; Bioterrorism; Smallpox

Resumo A varíola acompanhou o homem por muitos séculos, causando mortes e lesões graves e irreversíveis. Usada como arma biológica em situações de guerra, volta a ser tema de discussão no mundo exatamente por essa possibilidade, apesar de ter sido erradicada das Américas em 1971, e do mundo em 1977. Os dados acumulados durante as Campanhas de Erradicação, mostram que a infecção se disseminava com relativa lentidão, através de contato muito próximo do receptor com o paciente. Infecções sub-clínicas em não-vacinados eram raras e vacinações de bloqueio em torno de novos casos, desde que estes fossem identificados e confirmados com rapidez, eram capazes de impedir a disseminação da infecção. As transmissões indiretas através de aerossóis eram menos comuns. Vacinados mesmo uma única vez, raramente apresentavam doença grave, no caso de reinfecção. A possibilidade de uso do vírus da varíola como arma biológica deve ser considerada como real, apesar de, com base nos conhecimentos atuais, serem necessárias suspensões virais de alta potência, lançadas muito próximo das pessoas a serem atingidas em grande número.

Palavras-chave Controle de Doenças Transmissíveis; Bioterrorismo; Varíola 
A varíola teria surgido na Índia, sendo descrita na Ásia e na África desde antes da era cristã (McNeill, 1976). Sua presença constante e o medo que levava às populações geraram inúmeras lendas e cultos. Exemplos disso, são as divindades representando a doença, tanto na Índia como na África, esta última trazida para o Brasil e que se apresenta sempre com o rosto coberto, devido às cicatrizes causadas pela doença em seu rosto. Introduzida na Europa já na era cristã, a exemplo de outras doenças como a sífilis e a peste, a varíola atingia segmentos amplos da população, deixando um rastro de mortes, cegueira e cicatrizes irreversíveis.

Usada como arma biológica pelos exércitos de Cortez, no México, foi seguramente a principal responsável pela derrota dos astecas, que não possuíam qualquer imunidade contra a doença (McNeill, 1976). Ainda como arma biológica, foi utilizada por exércitos e colonizadores em suas lutas contra outras populações indígenas em várias regiões das Américas (Garrett, 1995).

No Brasil, a varíola foi referida pela primeira vez em 1563, na Ilha de Itaparica, na Bahia, disseminando-se para Salvador e causando grande número de casos e óbitos, principalmente entre os indígenas (MS, 1973a).

Passou à história, a prática milenar usada na Ásia e na África, de se infectar pessoas sadias que se queria imunizar contra a varíola, com material obtido de lesões de casos menos graves da doença, técnica denominada variolização, certamente com a ocorrência de casos graves em parte dos vacinados e a eventual transmissão de outras doenças.

No final do século XVIII, Edward Jenner, médico inglês, ao investigar em maior profundidade o fato de que ordenhadores, em contato com lesões de pele e úbere de bovinos, não se infectavam com a varíola ou apresentavam uma forma bem mais branda da doença, abriu uma nova perspectiva de controle da mesma. Com o material coletado dessas lesões, Jenner escarificava a pele de pessoas a quem desejava imunizar. A história registra o dia 14 de maio de 1796, no qual Jenner coletou material de uma lesão pustular nas mãos de uma ordenhadora de nome Sarah Nelmes e o inoculou na pele de James Phillips, vacinando-o contra a varíola (Fenner et al., 1989).

Apesar das críticas e receios com base em convicções religiosas e filosóficas, bem como a existência de efeitos colaterais, o medo da doença levou à rápida disseminação desta prática de infeção voluntária, desde o início do século XIX.

Amostras de vírus utilizadas para vacinação chegaram ao Brasil em torno de 1840, tra- zidas pelo Barão de Barbacena, sendo utilizadas principalmente na proteção de famílias nobres. Posteriormente, o cirurgião Barão de Pedro Afonso, criou um Instituto privado para o preparo de vacina anti-variólica no país, sendo mais tarde encarregado pelo governo de estabelecer o Instituto Municipal Soroterápico no Rio de Janeiro, posteriormente, Instituto Oswaldo Cruz (IOC).

Apesar de alguns sucessos isolados, vacinações mal organizadas nos países onde a varíola era endêmica e vacinas de qualidade duvidosa mantinham a doença nestas áreas como uma terrível realidade. Em 1958, a então União Soviética apresentou uma proposta à Organização Mundial da Saúde (OMS) em Genebra, no sentido de se estabelecer uma campanha internacional para a eliminação da varíola no mundo. Naquela ocasião, a varíola ainda ocorria em 33 países (Fenner et al., 1988; Garrett, 1995).

A região das Américas foi pioneira na estruturação da sua campanha. No Brasil, entre 1967 e 1971, se executou a chamada fase de ataque, com a vacinação sistemática de toda a população, alcançando-se um total de 81.745 .290 vacinados, em outubro de 1971, sendo que, em abril deste mesmo ano, havia sido diagnosticado o último caso no Brasil e nas Américas, na cidade do Rio de Janeiro (MS, 1973a). Após a fase de ataque, se implantou uma vacinação dirigida a algumas regiões e à população de 0-4 anos, tendo como meta a vacinação de $90 \%$ deste grupo. Em 1972, vacinaram-se 5.487.710 e em 1973, 5.701.521 pessoas de todas as idades, mostrando o grande esforço realizado para se impedir a volta da doença, que naqueles anos ainda persistia na Ásia e na África (MS, 1973b).

A vacinação foi sendo gradualmente desativada ao longo dos anos seguintes e, em 1976 1977, foi interrompida. Em conseqüência disso, toda a nossa população nascida após estes anos deve ser considerada susceptível à infecção por varíola.

A situação na África e na Ásia era, no entanto, bem diferente, e obstáculos de toda ordem se opunham à vacinação, como: motivos religiosos, lutas políticas, guerras e descrédito de grandes segmentos da população de que era possível alcançar a eliminação da doença.

Finalmente, em novembro de 1975, o diretor do programa de erradicação, D. A. Henderson, anunciou que Rehima Banu, uma menina de Bangladesh com três anos de idade, havia se curado e era o último caso de varíola na Ásia (Fenner et al., 1988).

Em 26 de outubro de 1977, foi anunciado o último caso de infeção natural pelo vírus da varíola no mundo, na área de Merka, Somália, em 
um paciente de nome Ali Maow Maalin. Para chegar a esse resultado, foi necessário um grande esforço devido ao início, em 1977, de uma guerra entre a Etiópia e a Somália, que trouxe o caos à região, com um milhão de refugiados deslocando-se para países vizinhos e áreas rurais (Garrett, 1995).

Em 1978, ocorreu na Inglaterra um caso fatal de varíola contraído em laboratório, quando, por falha nos cuidados de biossegurança, uma amostra de vírus atingiu um profissional que trabalhava em sala próxima ao local onde ele era manipulado, provavelmente, pelo duto de ventilação do prédio (Fenner et al., 1988).

Como assinalado, a região das Américas foi a primeira a erradicar a doença, sendo os 19 últimos casos detectados no Rio de Janeiro, no Parque Proletário, bairro da Penha, em abril de 1971, e as amostras identificadas no Laboratório de Referência de Varíola, por nós coordenado, no Departamento de Ciências Biológicas da Escola Nacional de Saúde Pública (ENSP), Fundação Oswaldo Cruz (FIOCRUZ). Este laboratório funcionou entre maio de 1968 e 1975, e examinou espécies de mais de trezentos casos suspeitos de varíola, recebidos de várias regiões do país (Schatzmayr \& Mesquita, 1970).

Além do trabalho deste laboratório, o IOC, sob a coordenação de Fonseca da Cunha, contribuiu para a Campanha Nacional de Erradicação da Varíola, com a fabricação de cerca de duzentos milhões de doses de vacina anti-variólica, preparadas em bovinos e em ovos embrionados. A vacina foi produzida igualmente pelo Instituto Butantan e, na fase inicial da campanha de imunização, pelo Instituto de Pesquisas Biológicas de Porto Alegre. A ENSP contribuiu ainda com a erradicação, ajudada por epidemiologistas de campo, que se envolveram diretamente na busca de casos de varíola no Brasil e em outros países do mundo.

O único reservatório conhecido de varíola é o próprio homem, e a maneira mais comum de transmissão da doença é a passagem do vírus por contato muito próximo, através de gotículas de saliva e secreções respiratórias contendo o agente. O contágio indireto a maiores distâncias, através de aerossóis, é bem menos comum (Dixon, 1962; Wehrle et al., 1970). O conceito portanto, de que um caso de varíola é capaz de gerar rapidamente centenas de novos casos, não tem respaldo científico nem foi observado quando dos trabalhos de erradicação em todo o mundo (Fenner et al., 1988). A varíola apresentava uma infecciosidade bem inferior ao sarampo, por exemplo, e os surtos se expandiam com relativa lentidão através do contato íntimo em comunidades fechadas ou se- mi-abertas, como ambientes familiares do paciente, hospitais (Wehrle et al., 1970) e mais raramente escolas.

Calculou-se que cada caso gerava entre 2 a 10 casos novos e que uma eficiente vigilância, com um diagnóstico laboratorial rápido e uma imediata intervenção de vacinação em torno dos casos, controlaria com muita eficiência a disseminação da doença, desde que o caso fosse rapidamente reconhecido (Henderson et al., 1999). Assim, o surgimento de casos de varíola em uma região não exigiria a vacinação imediata de toda a população de uma grande cidade, por exemplo. Hoje se preconiza, além da vacinação, a utilização de drogas inibidoras da replicação viral no paciente e em seus contatos (Bray et al., 2000; Henderson et al., 1999).

O período de incubação oscila em torno dos 12 a 14 dias e os sintomas começam com um período prodrômico de 2 a 3 dias, com febre elevada, mal estar e prostração, acompanhados de forte cefaléia e dor lombar. Após este período, surge a fase eruptiva, iniciando-se com um exantema maculo-papular que progride com pápulas (1 a 2 dias), depois vesículas por 2 a 3 dias, pústulas ao final da primeira semana de doença e finalmente, crostas que surgem cerca de 12 dias após o início dos sintomas. O exantema se inicia na mucosa oral, face e braços, progredindo para o tronco e membros. Lesões podem ser observadas na palma das mãos e pés, fato raramente observado na varicela (CDC, 2001; Dixon, 1962).

Na varíola, as lesões na pele surgem como uma única onda, ao contrário da varicela, que pode apresentar vesículas, pústulas e crostas ao mesmo tempo no paciente. As lesões de varíola apresentam-se firmemente embebidas na derme e são sentidas como estruturas rígidas, circulares, elevadas e com alguns milímetros de tamanho. Com a regressão das lesões, as crostas se soltam, e na cicatrização podem permanecer marcas irreversíveis na pele, em especial quando as lesões foram muito numerosas, com tendência a se confluir (CDC, 2001; Dixon, 1962; Fenner et al., 1989). O diagnóstico laboratorial pode ser feito em poucas horas, através do exame ao microscópio eletrônico do material coletado nas fases de vesículas, pústulas ou crostas. O grupo Pox (varíola-vaccínia) apresenta uma morfologia característica, que permite distingui-lo com segurança da varicela, que é o diagnóstico diferencial mais comum a ser considerado. Métodos moleculares como a reação de PCR, são também aplicados ao diagnóstico, permitindo caracterizar os diversos membros do grupo Pox, separando a varíola dos demais vírus do grupo. 
Embora a eficácia da vacinação, por motivos éticos, nunca tenha sido avaliada em testes de campo do tipo duplo-cego, estudos epidemiológicos demonstraram uma sólida imunidade cinco anos após a vacinação primária e uma imunidade menor, porém ainda persistente, por pelo menos dez anos (El-Ad et al., 1990). A administração da vacina dentro dos primeiros dias após a exposição inicial pode reduzir ou mesmo prevenir a doença. Em um indivíduo com uma função imunológica normal, anticorpos neutralizantes aparecem aproximadamente dez dias após a vacinação primária e sete dias após a revacinação (CDC, 2001). Embora o nível mínimo de anticorpos protetores contra a varíola não seja conhecido, reconhece-se que a administração percutânea de uma dose standard de vacina em primovacinados gera uma resposta de anticorpos em mais de $95 \%$ dos vacinados. Anticorpos neutralizantes persistem em $75 \%$ dos vacinados, por dez anos, e por cerca de trinta anos nos indivíduos que receberam três doses da vacina (El-Ad et al., 1990; Lublin-Tennenbaum et al., 1990).

Em relação à mortalidade por varíola, na Ásia e na África se observavam taxas em torno de $20 \%$, sendo que a maior mortalidade observada ocorreu em uma epidemia no Kuwait na década de 60 , com $43 \%$ de casos fatais (Fenner et al., 1988). Em alguns pacientes podiam ser observadas formas de evolução mais severas da doença, com toxemia, lesões hemorrágicas e confluentes, evoluindo ao óbito em 4 a 5 dias após o aparecimento do exantema. Fatores individuais deveriam estar envolvidos nestas formas de evolução rápida, considerando que a imunidade celular é muito importante na varíola (Fenner, 1989).

Nas Américas, as taxas de mortalidade no início do século XX se igualavam às de outros países do mundo, porém, amostras de baixa virulência e mortalidade abaixo de $3 \%$, começaram a predominar ao longo dos anos. As amostras do chamado alastrim, exceto por sua baixa virulência, tinham todas as propriedades biológicas da varíola e não se conhece como ocorreu esta modificação, que pelos relatos disponíveis, teria surgido no Caribe. No Brasil, a taxa de letalidade durante a Campanha de Erradicação, oscilou entre 1,6\% em 1967 e 0,8\% em 1970 (MS, 1973a).

A varíola foi declarada erradicada das Américas em 1973, com base no parecer da Comissão Internacional que se reuniu na FIOCRUZ em outubro daquele ano (MS, 1973b). A erradicação em todo o mundo foi anunciada pela OMS em maio de 1980, durante a sua Assembléia Geral (Fenner et al., 1988).
Tendo em vista os riscos do surgimento de casos a partir de amostras guardadas nos laboratórios que executaram o diagnóstico laboratorial, foram os mesmos solicitados a destruilas, permanecendo algumas amostras de vírus vivo e completo em apenas dois laboratórios do mundo, um nos Estados Unidos e outro na Rússia. Um Comitê Técnico para os chamados Orthopoxvírus (varíola e vírus correlatos), do qual participamos desde 1996, foi organizado pela OMS, inicialmente para acompanhar o período pós-erradicação e monitorar possíveis problemas que viessem a surgir, e posteriormente, para definir se e quando as amostras de varíola ainda existentes deveriam ser destruídas. Em 1999, este grupo passou a ser denominado de Comitê Técnico para Pesquisas sobre Varíola, com a responsabilidade de aprovar e monitorar a execução de projetos de pesquisa, envolvendo as amostras mantidas nos dois laboratórios citados.

A questão da destruição das amostras ainda existentes gerou uma grande polêmica e, apesar da maioria do Comitê recomendar seguidas vezes a destruição, esta nunca foi aprovada pela Assembléia Geral da OMS, que deverá dar a palavra final. A última data limite acertada foi 31 de dezembro de 2002, porém, os últimos acontecimentos de atuação de grupos terroristas, trouxeram ainda mais indefinições ao problema.

Em realidade, se está hoje trabalhando em três grandes linhas de pesquisa em varíola, quais sejam o desenvolvimento de novas e mais potentes vacinas, novos métodos de diagnóstico laboratorial e o desenvolvimento de novas drogas para tratamento. Para todas estas linhas de pesquisa são necessários vírus vivos e estudos em modelos experimentais em animais, especialmente primatas, com o que não se pode hoje prever até quando os vírus da varíola serão mantidos como até o momento.

Uma questão fundamental é o risco real do vírus da varíola, ser utilizado caso exista fora dos dois laboratórios citados, como uma arma biológica capaz de se disseminar em largos segmentos da população.

Como assinalado, a transmissão da varíola exige um contato próximo do caso com o receptor. Calculou-se que na grande maioria dos casos, o receptor havia permanecido a uma distância mínima de dois metros do paciente e tido com ele um contato estreito (CDC, 2001). Assinale-se que as infeções por varíola sem manifestações clínicas em indivíduos não vacinados eram raras, ou seja, quase sempre ocorriam no paciente os sintomas gerais e as lesões na pele. Com isso, ele era reconhecido pela co- 
munidade e pelos sistemas de vigilância da doença. Este dado permitiu que, em torno de cada novo caso que surgia, se estabelecesse uma vacinação de contatos, bloqueando a disseminação da doença. Esta metodologia seria a mais aplicável nas atuais circunstâncias, em que as populações mais jovens não foram vacinadas contra a doença.

Pelos fatos descritos, a disseminação criminosa do vírus sob forma de aerossóis exigiria uma grande quantidade de vírus, com altos títulos infectantes e que deveriam ser lançados muito próximo das pessoas a serem infectadas, de maneira a serem absorvidos por grande número delas. Estes sistemas, embora teoricamente viáveis, exigiriam sofisticados processos de implantação e apresentam problemas técnicos consideráveis (Henderson et al., 1999).

Recente documento da OMS reforça o conceito de que, no momento, uma vacinação extensa de populações contra a varíola não é recomendada, e que as pessoas que foram vacinadas no passado, dificilmente desenvolveriam sintomas graves da doença. A OMS considera ainda que o eventual surgimento de um caso de varíola no mundo seria tratado como uma emergência internacional, e que todos os recur- sos disponíveis seriam colocados em ação para imediato controle do episódio (WHO, 2001).

Pode-se concluir, portanto, que ao contrário do que geralmente se acredita, a varíola não é uma doença de altíssima letalidade e que se espalharia com grande rapidez na comunidade, se por um ato terrorista surgissem casos em uma determinada região, nem seria necessário vacinar imediatamente toda uma cidade ou todo o país. No entanto, para que seja possível uma pronta resposta no caso de surgimento de casos de varíola, é essencial o preparo dos sistemas de saúde para reconhecer casos suspeitos e coletar material para envio a laboratórios de referência, devidamente capacitados a oferecer uma rápida resposta, permitindo implantar a vacinação de bloqueio em torno do eventual caso, além da aplicação de drogas anti-virais (CDC, 1999; Henderson, 1996; Korterpeter \& Parker, 1999).

Não por último, assinale-se que o ressurgimento da varíola através de atos de terrorismo representaria um triste retrocesso para toda a humanidade, sob qualquer ponto de vista, considerando-se os esforços feitos por milhares de pessoas em todo o mundo para se alcançar a erradicação da varíola no nosso planeta.

\section{Referências}

BRAY, M.; MARTINEZ, M.; SMEE, D. F.; KEFAUER, D.; THOMPSON, E. \& HUGGINS, J. W., 2000. Cifovir protects mice against lethal aerosol or intranasal cow-pox virus challenge. Journal of Infectious Diseases, 181:10-19.

CDC (Centers for Disease Control and Prevention), 1999. Bioterrorism Readiness Plan: A Template for Healthcare Facilities. Atlanta: Advisory Committee on Infectious Control, CDC.

CDC (Centers for Diseases Control and Prevention), 2001. Vaccinia (smallpox) vaccine: Recommendations of the Advisory Committee on Immunization Practices (ACIP), 20001. MMWR, 50.

DIXON, C. W., 1962. Smallpox. London: Churchill.

EL-AD, B.; ROTH, Y. \& WINDER, A., 1990. Persistence of neutralizing antibodies after revaccination against smallpox. Journal of Infectious Diseases, 161:446-448.

FENNER, F.; HENDERSON, D. A.; ARITA, I.; JEZEK, Z. \& LADNY, I. D., 1988. Smallpox and its Eradication. Geneva: World Health Organization.

FENNER, F; WITTEK, R. \& DUMBELL, K. R., 1989. Orthopoxviruses. San Diego: Academic Press. 
GARRET, L., 1995. The Coming Plague. New York: Farrar, Straus \& Giroux.

HENDERSON, D. A., 1996. The global status of smallpox eradication. In: Seminar on Smallpox Eradication and Measles Control in Western and Central Africa, Proceedings, pp. 1-12. Lagos: Center for Disease Control and Prevention.

HENDERSON, D. A., 1999. Looming threat of bioterrorism. Science, 283:1279-1282.

HENDERSON, D. A.; INGLESBY, T. V. \& BARTLETT, J. G., 1999, Smallpox as a biological weapon: Medical and public health management. JAMA, 281: 2127-2137.

KORTEPETER, M. G. \& PARKER, G. W., 1999. Potential biological weapons threats. Emerging Infectious Diseases, 5:523-527.

LUBLIN-TENNENBAUM, T.; KATZENELSON, E.; ELAD, B. \& KATZ, E., 1990. Correlation between cutaneous reaction in vaccinees immunized against smallpox and antibody titer determined by plaque neutralization test and ELISA. Viral Immunology, 3:19-25.
McNEILL, W. H., 1976. Plagues and People. New York: Doubleday.

MS (Ministério da Saúde), 1973a. Boletim da Campanha de Erradicação da Varíola, 7(8):1-27.

MS (Ministério da Saúde), 1973b. Boletim da Campanha de Erradicação da Varíola, 7(18):1-5.

WHO (World Health Organization), 2001. World Health Organization Announces Updated Guidance on Smallpox Vaccination. 26 October $2001<\mathrm{http}$ /// www.who.int/inf-pr-2001/en/state2001-16.html>.

SCHATZMAYR, H. G. \& MESQUITA, J. A., 1970. Examen de espécimens para el diagnóstico de la viruela en un laboratorio del Brasil. Boletín de la Oficina Sanitaria Panamericana, 69:500-504.

WEHRLE, P. F.; POSCH, J.; RICHTER, K. H. \& HENDERSON, D. A., 1970. Airborne outbreak of smallpox in a German hospital and its significance with respect to other recent outbreaks in Europe. Bulletin of the World Health Organization, 43: 669-679. 